$9-1-2011$

\title{
The Effect of Tamoxifen and Raloxifene on Estrogen Metabolism and Endometrial Cancer Risk
}

Marian Y. Williams-Brown

Sana M. Salih

Xia Xu

Timothy D. Veenstra

Muhammad Saeed

See next page for additional authors

Follow this and additional works at: https://digitalcommons.cedarville.edu/

pharmaceutical_sciences_publications

Part of the Pharmacy and Pharmaceutical Sciences Commons

This Article is brought to you for free and open access by DigitalCommons@Cedarville, a service of the Centennial Library. It has been accepted for inclusion in Pharmaceutical Sciences Faculty Publications by an authorized administrator of DigitalCommons@Cedarville. For more information, please contact digitalcommons@cedarville.edu. 


\section{Authors}

Marian Y. Williams-Brown, Sana M. Salih, Xia Xu, Timothy D. Veenstra, Muhammad Saeed, Shaleen K. Theiler, Concepcion R. Diaz-Arrastia, and Salama A. Salama 


\title{
The effect of tamoxifen and raloxifene on estrogen metabolism and endometrial cancer risk
}

\author{
Marian Y. Williams-Brown ${ }^{a}$, Sana M. Salih ${ }^{b}, X_{1 a} \mathrm{Xu}^{\mathrm{c}}$, Timothy D. Veenstra ${ }^{\mathrm{c}}$, Muhammad Saeed $^{\mathrm{d}}$, \\ Shaleen K. Theiler ${ }^{\mathrm{a}, \mathrm{e}}$, Concepcion R. Diaz-Arrastia ${ }^{\mathrm{a}, \mathrm{e}}$, Salama A. Salama ${ }^{\mathrm{a}, \mathrm{e}, *}$
}

a Department of Obstetrics \& Gynecology, University of Texas Medical Branch, 301 University Blvd., Galveston, TX 77555-0587, United States

${ }^{\mathrm{b}}$ Department of Obstetrics and Gynecology, University of Wisconsin, 600 Highland Ave, Madison, WI 53792, United States

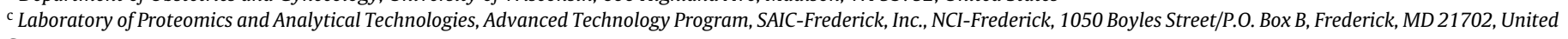
States

${ }^{\mathrm{d}}$ Eppley Institute for Research in Cancer and Allied Diseases, University of Nebraska Medical Center, 986805 Nebraska Medical Center, Omaha, NE 68198, United States

e Department of Obstetrics and Gynecology, Baylor College of Medicine, One Baylor Plaza MS: BCM 610, Houston, TX 77030, United States

\section{A R T I C L E I N F O}

\section{Article history:}

Received 30 November 2010

Received in revised form 22 March 2011

Accepted 3 May 2011

\section{Keywords:}

Endometrial cancer

Estrogen metabolism

Tamoxifen

Raloxifene

\begin{abstract}
A B S T R A C T
Selective estrogen receptor modulators (SERMs) demonstrate differential endometrial cancer (EC) risk While tamoxifen (TAM) use increases the risk of endometrial hyperplasia and malignancy, raloxifene (RAL) has neutral effects on the uterus. How TAM increases the risk of EC and why TAM and RAL differentially modulate the risk for EC, however, remain elusive. Here, we tested the hypothesis that TAM increases the risk for EC, at least in part, by enhancing the local estrogen biosynthesis and directing estrogen metabolism towards the formation of genotoxic and hormonally active estrogen metabolites. In addition, the differential effects of TAM and RAL in EC risk are attributed to their differential effect on estrogen metabolism/metabolites. The endometrial cancer cell line (Ishikawa cells) and the nonmalignant immortalized human endometrial glandular cell line (EM1) were used for the study. The profile of estrogen/estrogen metabolites (EM), depurinating estrogen-DNA adducts, and the expression of estrogen-metabolizing enzymes in cells treated with 17 $\beta$-estradiol (E2) alone or in combination with TAM or RAL were investigated using high performance liquid chromatography-electrospray ionizationtandem mass spectrometry (HPLC-ESI-MS ${ }^{2}$ ), ultraperformance liquid chromatography/tandem mass spectrometry (UPLC-MS/MS), and Western blot analysis, respectively. TAM significantly increased the total EM and enhanced the formation of hormonally active and carcinogenic estrogen metabolites, 4-hydroxestrone (4-OHE1) and 16 $\alpha$-hydroxyestrone, with concomitant reduction in the formation of antiestrogenic and anticarcinogenic 2-hydroxyestradiol and 2-methoxyestradiol. Furthermore, TAM increased the formation of depurinating estrogen-DNA adducts 4-OHE1 [2]-1-N7Guanine and 4-OHE1 [2]-1-N3 Adenine. TAM-induced alteration in EM and depurinating DNA adduct formation is associated with altered expression of estrogen metabolizing enzymes CYP1A1, CYP1B1, COMT, NQO1, and SF-1 as revealed by Western blot analysis. In contrast to TAM, RAL has minimal effect on EM, estrogen-DNA adduct formation, or estrogen-metabolizing enzymes expression. These data show that TAM perturbs the balance of estrogen-metabolizing enzymes and alters the disposition of estrogen metabolites, which can explain, at least in part, the mechanism for TAM-induced EC. These results also implicate the differential effect of TAM and RAL on estrogen metabolism/metabolites as a potential mechanism for their disparate effects on the endometrium.
\end{abstract}

(c) 2011 Elsevier Ltd. All rights reserved.

\footnotetext{
Abbreviations: SERM, selective estrogen receptor modulator; EC, endometrial cancer; TAM, tamoxifen; RAL, raloxifene; EM1, nonmalignant immortalized human

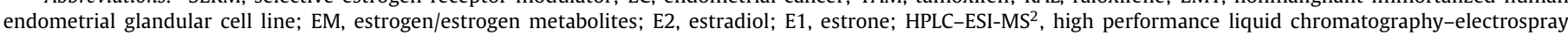

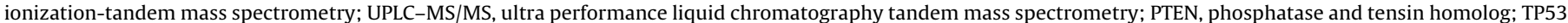

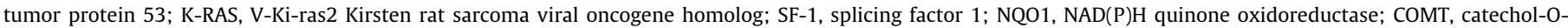

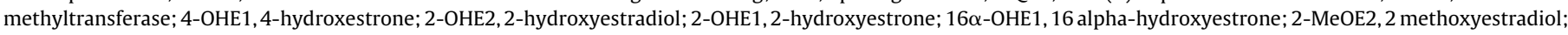

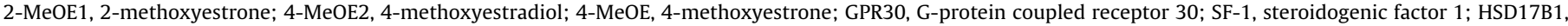
hydroxysteroid (17 beta) dehydrogenase 1; ERE, estrogen responsive element; EpRE, electrophile response element.

* Corresponding author at: Department of Obstetrics and Gynecology, Baylor College of Medicine, One Baylor Plaza MS: BCM 610, Houston, TX 77030, United States. Tel.: +1 832824 4188; fax: +1 8328254190 .

E-mail addresses: mywillia@utmb.edu (M.Y.Williams-Brown), salih@wisc.edu (S.M. Salih), XuX@mail.nih.gov (X.Xu),veenstrat@mail.nih.gov (T.D. Veenstra), msaeed@unmc.edu (M. Saeed), shaleen.theiler@yahoo.com (S.K. Theiler), arrastia@bcm.tmc.edu (C.R. Diaz-Arrastia), salama@bcm.edu (S.A. Salama).
} 


\section{Introduction}

Tamoxifen (TAM), the first selective estrogen receptor modulator (SERM) available for clinical use, is regarded as a highly effective agent for the prevention and treatment of breast cancer. However, the long-term use of TAM is associated with endometrial thickening, dysfunctional uterine bleeding, endometrial polyps, endometrial hyperplasia, and endometrial cancer [1-3]. By contrast, raloxifene (RAL), another member of the SERM class of drugs, currently approved for the prevention and treatment of postmenopausal osteoporosis and for the prevention of breast cancer, seems to have neutral effects on endometrium [4]. Although, both TAM and RAL apparently have a similar mechanism of action, the molecular mechanism underlying their different effects on endometrium and the mechanism whereby TAM imposes increased risk for EC are not clear. Understanding the relevant pathways involved in TAM-associated EC is a matter of great importance to allow more accurate assessment of the risk to women receiving TAM treatment or, more importantly, to develop chemoprevention approaches. Several attempts have been made to understand the mechanism of TAM-associated EC. Nevertheless, there are lingering controversies surrounding the proposed mechanisms, and the resulting data is not conclusive. It has been postulated that the association of TAM with EC is attributed to certain TAM metabolites, which are able to bind to DNA to form adducts and cause DNA damage [5-9]. However, analysis of TAM-DNA adducts in endometrial tissues from women treated with TAM has yielded mixed results [10]. Even though TAM-DNA adduct formation is possible in human tissues, it may only occur in a proportion of patients, and in such cases, the levels are likely to be very low; therefore, proving a causal link between the presence of specific TAM-DNA adducts and the development of EC is extremely difficult. Thus, whether TAM-DNA adducts contribute to the development of EC depends on whether they can actually be formed in endometrial tissues and on the type of specific molecular and cellular responses they induce, if present. Indeed, it has been reported that TAM-DNA adducts are formed in immortalized human hepatocytes but not in human endometrial carcinoma cells, suggesting that TAM-DNA adduct formation may not be an absolute requirement for the development of EC $[11,12]$. In addition, several investigators found no evidence for the presence of TAM-DNA adducts in endometrial DNA from women who had undergone TAM therapy for extended period of time, even by using the more sensitive and specific HPLC-electrospray ionization-tandem mass spectrometry (HPLC-ESI-MS/MS) assay [13-17]. This apparent inconsistency in the data suggests that although TAM-adduct formation may occur at a very low level in a proportion of patients, an alternative/complementary mechanism underlying TAM-induced EC may also be a factor. Plausible evidence suggests that the effect of TAM on the endometrium is mediated, at least in part, by modulating estrogen biosynthesis and metabolism. First, several reports indicate that aromatase inhibitors prevent endometrial growth and reverse TAM-induced uterine changes in postmenopausal breast cancer patients $[18,19]$. Secondly, molecular genetic studies indicate that genetic alterations associated with Type I endometrial carcinomas-commonly associated with TAM use-include mutations in PTEN, K-RAS, and the formation of microsatellite instabilities [20]. These alterations have been found to be induced by certain estrogen metabolites in human endometrial glandular epithelial cells [21]. In addition, mounting evidence suggests that TAM modulates gene expression of estrogen biosynthesis and metabolism. For instance, it has been reported that TAM increases SF-1 transcription and induces the SF-1 target gene aromatase expression, regulates the activities of 17 beta-hydroxysteroid dehydrogenase activity and $\mathrm{NAD}(\mathrm{P}) \mathrm{H}$ : quinone oxidoreductase (NQO1), and increases the 16 alpha-hydroxylation of estrogen [22-27]. Thus, these notions led us to hypothesize that TAM increases the risk for EC, at least in part, by enhancing the local estrogen biosynthesis and directing estrogen metabolism towards the formation of genotoxic and hormonally active estrogen metabolites. We also propose that differential effects of TAM and RAL in EC risk can be explained by their differential effects on estrogen metabolism/metabolites. This is a novel approach as the mainstream focus of study regarding TAMassociated endometrial cancer has been on the effects of TAM on DNA or the effects of estrogen on endometrial tissues. Our approach specifically investigates the effect of TAM on estrogen metabolism, and we propose that this relationship directly contributes to the increased risk of endometrial cancer.

\section{Materials and methods}

\subsection{Cells and cell culture}

Immortalized nonmalignant human endometrial glandular cell line (EM1), which express both estrogen and progesterone receptors and retain the function and characteristic of the primary cells, were a gift from Dr. Satoru Kyo (Department of Obstetrics and Gynecology, Kanazawa University School of Medicine, Kanazawa, Japan) [28]. The endometrial cancer cell line, Ishikawa, was obtained from the American Type Culture Collections (ATCC, Manassas, VA). EM1 and Ishikawa cells were maintained in 5\% $\mathrm{CO}_{2}$ /air in Dulbecco's minimal essential medium (DMEM), free of serum and phenol red and supplemented with $10 \%$ fetal bovine serum and $1 \%$ antibiotic-antimycotic solution. Forty-eight hours before the treatment, the cells were weaned in serum-free media. Then, the cells were treated with E2 $(10 \mathrm{nM})$ alone or in combination with increasing concentrations $(100 \mathrm{nM}$ to $10 \mu \mathrm{M})$ of either 4-hydroxytamoxifen (4OH-TAM), which is the active form of tamoxifen, or RAL. Forty-eight hours later, the media were collected and stored at $-80^{\circ} \mathrm{C}$ until used for the analysis of estrogen metabolites and estrogen-DNA adducts. We also collected the treated cells for RNA and protein extraction.

\subsection{Determination of estrogen/estrogen metabolites in the growth media}

The levels of estrogen and estrogen metabolites (EM) were determined by testing the conditioned media from cells treated with E2 and/or different doses of $40 \mathrm{OH}-\mathrm{TAM}$ or RAL according to the methods described by Xu et al. [29]. Briefly, $5 \mu \mathrm{L}$ of the stable isotope labeled estrogen and estrogen metabolite (SI-EM) working internal standard solution ( $40 \mathrm{pg}$ SI-EM) was added to $400 \mu \mathrm{L}$ cell medium aliquot followed by $500 \mu \mathrm{L}$ of $0.15 \mathrm{M}$ sodium acetate buffer ( $\mathrm{pH} 4.6)$ containing $0.25 \%(\mathrm{w} / \mathrm{v})$ L-ascorbic acid. Dichloromethane $(6 \mathrm{~mL})$ was added to the sample, which then underwent inverse extraction at $8 \mathrm{rpm}$ (RKVSD ${ }^{\mathrm{TM}}$, ATR, Inc., Laurel, MD) for $30 \mathrm{~min}$. After extraction, the aqueous layer was discarded, and the organic solvent portion was transferred into a clean glass tube and evaporated to dryness under a stream of nitrogen gas at $60^{\circ} \mathrm{C}$ (Reacti-Vap III $^{\mathrm{TM}}$, Pierce, Rockford, IL). The dried sample residue was then redissolved in $40 \mu \mathrm{L}$ of $0.1 \mathrm{M}$ sodium bicarbonate buffer ( $\mathrm{pH} \mathrm{9.0)}$ and $40 \mu \mathrm{L}$ of dansyl chloride solution $(1 \mathrm{mg} / \mathrm{mL}$ in acetone). After sonication, the sample was heated at $60^{\circ} \mathrm{C}$ (Reacti-Therm III ${ }^{\mathrm{TM}}$ Heating Module, Pierce, Rockford, IL) for $5 \mathrm{~min}$ to form the EM and SIEM dansyl derivatives (EM-dansyl and SI-EM-dansyl), respectively. After derivatization, all samples were analyzed using high performance liquid chromatography-electrospray ionization-tandem mass spectrometry (HPLC-ESI-MS ${ }^{2}$ ). Capillary HPLC-ESI-MS ${ }^{2}$ analysis was performed using an Agilent 1200 series nanoflow LC system (Agilent Technologies, Palo Alto, CA) coupled to a $\mathrm{TSQ}^{\mathrm{TM}}$ Quantum Ultra triple quadrupole mass spectrometer (Thermo 
Electron, San Jose, CA). Quantitation of cell medium estrogen metabolites was carried out using Xcalibur ${ }^{\mathrm{TM}}$ Quan Browser (Thermo Electron) as previously described [29]. According to this method, we were capable of quantifying simultaneously 15 estrogens and estrogen metabolites: estrone and its 2-, 4-, and 16-alpha-hydroxy and 2- and 4-methoxy derivatives; 2hydroxyestrone-3-methyl ether; 17beta-E2 and its 2-hydroxy and 2- and 4-methoxy derivatives; and estriol, 17-epiestriol, 16ketoestradiol, and 16-epiestriol. This experiment was done in collaboration with Dr. Timothy Veenestra (NCI, Frederick, MD).

\subsection{HPLC analysis of estrogen-induced depurinating DNA adducts}

The EM1 and Ishikawa cells were treated as described above. The growth medium was used to measure the level of depurinating estrogen-DNA adducts according to the method described by Zahid et al. [30]. Briefly, cell culture medium was extracted by using Varian C8 Certify II solid phase extraction cartridge (Varian, Harbor City, CA). The cartridges were preequilibrated by sequentially passing $1 \mathrm{~mL}$ methanol, distilled water, and potassium phosphate buffer (100 mM, pH 8.0) through them. Culture medium was adjusted with $1 \mathrm{~mL}$ of $1 \mathrm{M}$ potassium phosphate to $\mathrm{pH} 8$ and passed through the cartridge. After washing with $2 \mathrm{~mL}$ of $100 \mathrm{mM}$ potassium phosphate and $5 \mathrm{~mL}$ of distilled water, the analytes were eluted with $1 \mathrm{~mL}$ of elution buffer comprised of methanol/acetonitrile/water/TFA (8:1:1:0.1). The eluent was evaporated to about $100 \mu \mathrm{L}$ by using a Jouan RC10 Vacuum Concentrator and reconstituted with $100 \mu \mathrm{L}$ of $\mathrm{MeOH} /$ water (1:1). The solution was then passed through $5000 \mathrm{MW}$ cut off filters and analyzed on HPLC connected with multiple electrochemical detectors.

\subsection{HPLC analysis of adducts}

Analyses of all samples were conducted on an HPLC system equipped with a dual ESA Model 580 autosampler, and a 12-channel CoulArray electrochemical detector (ESA, Chelmsford, MA). The 2 mobile phases used were (A) acetonitrile/methanol/buffer/water (15:5:10:70) and (B) acetonitrile/methanol/buffer/water (50:20:10:20). The buffer was a mixture of $0.25 \mathrm{M}$ citric acid and $0.5 \mathrm{M}$ ammonium acetate in tripledistilled water, and the $\mathrm{pH}$ was adjusted to 3.6 with acetic acid. The $95 \mu \mathrm{L}$ injections were carried out on a Phenomenex Luna${ }^{2} \mathrm{C}-{ }^{18}$ column $(250 \mathrm{~mm} \times 4.6 \mathrm{~mm}$ ID, $5 \mathrm{~mm}$; Phenomenex, Torrance, CA), initially eluted isocartically at $90 \% \mathrm{~A} / 10 \% \mathrm{~B}$ for $15 \mathrm{~min}$, followed by a linear gradient to $90 \% \mathrm{~B} / 10 \% \mathrm{~A}$ in the next $40 \mathrm{~min}$, and held there for $5 \mathrm{~min}$ (total $50 \mathrm{~min}$ gradient) at a flow rate of $1 \mathrm{~mL} / \mathrm{min}$ and a temperature of $30^{\circ} \mathrm{C}$. The serial array of 12 coulometric electrodes was set at potentials of $-35,10,70,140,210,280,350,420$, $490,550,620$, and $690 \mathrm{mV}$. The system was controlled, and the data were acquired and processed using the CoulArray software package (ESA). Peaks were identified by both retention time and peak height ratios between the dominant peaks and the peaks in the 2 adjacent channels. The metabolites, conjugates, and depurinating adducts were quantified by comparison of peak response ratios with known amounts of standards. The level of adducts were normalized against cell numbers and the DNA contents.

\subsection{Western blot analysis}

EM-1 and Ishikawa were treated with E2 alone or in combination with increasing concentrations of $4 \mathrm{OH}-\mathrm{TAM}$ and RAL as previously described. And after $72 \mathrm{~h}$, the cells were washed with phosphatebuffered saline (PBS), and whole cell lysates were prepared with RIPA lysis buffer. The cell lysates were solubilized in sample buffer $(60 \mathrm{mM}$ Tris-hydrochloride $[\mathrm{HCl}], \mathrm{pH} 6.8 ; 2 \%$ sodium dodecyl sulfate [SDS]; $10 \%$ glycerol; $0.7 \mathrm{~mol} / \mathrm{L} 2-\beta$-mercaptoethanol;
0.01\% bromophenol blue) and subjected to SDS-polyacrylamide gel electrophoresis (PAGE). Proteins were electroblotted onto nitrocellulose membranes. Membranes were immunoblotted with the primary antibody against COMT, NQO1, CYP1A1, CYP1B1, or $\beta$ actin. After washing, membranes were incubated with horseradish peroxidase (HRP)-conjugated secondary antibodies (Vector Laboratories, Burlingame, CA). The intensity of each protein band was determined using a scanning densitometer (Epson 4870, Epson America, Long Beach, CA).

\subsection{Statistical analyses}

Absolute concentrations of individual estrogen metabolites (EM) were normalized against protein concentrations and expressed as picomoles per microgram protein per $48 \mathrm{~h}$. As previously described by Eliassen, individual EM were combined according to chemical characteristics (e.g., catechols and methylated catechols) and pathways (e.g., 2-hydroxylation, 4hydroxylation, and 16-hydroxylation pathways), and absolute concentrations of these EM groups were calculated by summing the individual EM in the group [31]. Total estrogen metabolites were calculated as the sum of each of the 15 EM. Percents of EM were obtained by dividing the individual or grouped EM by the total EM. Ratios of selected EM groups also were calculated. Although, we did not assess most ratios of individual EM, we evaluated the certain ratios, which are considered potential predictors of endometrial cancer risk. Statistical analyses were conducted using SAS v. 9.1 (SAS Institute, Cary, NC). Data are presented as the mean \pm standard error of the mean $(M \pm S E M)$ for each experiment. Absolute levels of each EM were expressed in picomoles per milligram protein. Relative EM levels (\% EMet) were expressed as a percentage of total EM. Statistical significance between different treatments was determined by 1-way analysis of variance (ANOVA) followed by post hoc comparison using Student $t$-test.

\section{Results}

\subsection{Total EM in endometrial cells treated with E2 with or without TAM or RAL}

To evaluate the effects of TAM or RAL on estrogen metabolism, the sum of the absolute levels of total EM was measured in conditioned media from EM1 and Ishikawa cells treated with E2 (10 nM) alone or in combination with different concentrations $(100 \mathrm{nM}$ or $1 \mu \mathrm{M})$ of TAM or RAL. As indicated in Table 1 , the total estrogens and estrogen metabolites were significantly higher in the media from EM1 cells treated with E2 (10 nM) plus TAM (100 nM or $1 \mu \mathrm{M})$ compared with cells treated with E2 $(10 \mathrm{nM})$ alone. In contrast, treatment with RAL did not significantly affect the total EM compared with cells treated with E2 alone (Table 1). Likewise, a similar profile of EM was obtained from Ishikawa cells under similar treatment conditions (Table 2).

\subsection{Profile of specific EM in endometrial cells treated with E2 with or without TAM or RAL}

We assessed the effect of TAM or RAL on the level of certain estrogen metabolites in conditioned media with unique and known roles in estrogen-induced EC. The estrogen metabolite 2-OHE2 has weak estrogenic or even antiestrogenic effects and, therefore, influences the hormonal and carcinogenic effects of estrogen. Thus, we assessed the rate of 2-OHE2 formation in cells treated with E2 alone or in combination with TAM or RAL. Our data indicated that 2-OHE2 is one of the major EM detected in conditioned media from EM1 and Ishikawa cells. As illustrated in Table 1, in EM1 cells treated with E2 alone, the rate of 2-OHE2 formation was $3.7 \pm 0.4 \%$ 
Table 1

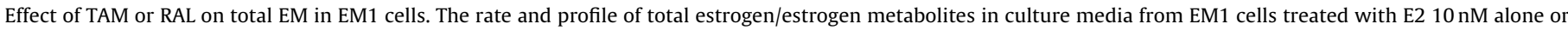

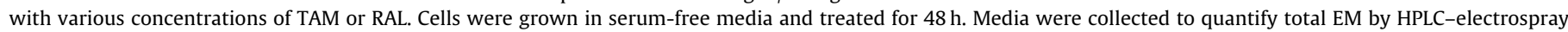
ionization-tandem mass spectrometry. Data were normalized against protein concentration.

\begin{tabular}{|c|c|c|c|c|c|}
\hline \multirow[t]{2}{*}{ Mean } & \multicolumn{5}{|c|}{ pmole/mg protein $/ 48 \mathrm{~h}$ (\% from the total) } \\
\hline & E2 alone (10 nM) & $\mathrm{E} 2+\mathrm{TAM}(100 \mathrm{nM})$ & $\mathrm{E} 2+\mathrm{TAM}(1 \mu \mathrm{M})$ & $\mathrm{E} 2+\mathrm{RAL}(100 \mathrm{nM})$ & $\mathrm{E} 2+\mathrm{RAL}(1 \mu \mathrm{M})$ \\
\hline \multicolumn{6}{|l|}{ Parent estrogens } \\
\hline Estrone (E1) & $\begin{array}{l}530 \pm 60 \\
(12 \pm 3)\end{array}$ & $\begin{array}{l}340 \pm 20 \\
(7 \pm 1)\end{array}$ & $\begin{array}{l}310 \pm 80 \\
(6 \pm 3)\end{array}$ & $\begin{array}{l}590 \pm 40 \\
(15 \pm 4)\end{array}$ & $\begin{array}{l}420 \pm 30 \\
(10 \pm 7)\end{array}$ \\
\hline Estradiol (E2) & $\begin{array}{l}3500 \pm 100 \\
(83 \pm 1)\end{array}$ & $\begin{array}{l}4690 \pm 70 \\
(91.4 \pm 0.4)\end{array}$ & $\begin{array}{l}5200 \pm 300 \\
(93 \pm 1)\end{array}$ & $\begin{array}{l}3000 \pm 100 \\
(80 \pm 1)\end{array}$ & $\begin{array}{l}3900 \pm 300 \\
(87.1 \pm 0.6)\end{array}$ \\
\hline \multicolumn{6}{|l|}{ 2-Hydroxylation pathway EM catechols } \\
\hline 2-Hydroxyestrone (2-OHE1) & $1.760 \pm 0.007$ & $0.94 \pm 0.11^{*}$ & $1.05 \pm 0.05^{*}$ & $1.84 \pm 0.04$ & $1.92 \pm 0.08$ \\
\hline 2-Hydroxyestradiol (2-OHE2) & $\begin{array}{l}157 \pm 17 \\
(3.7 \pm 0.4)\end{array}$ & $\begin{array}{l}90 \pm 8^{*} \\
(1.80 \pm 0.02)\end{array}$ & $\begin{array}{l}75 \pm 1^{*} \\
(1.30 \pm 0.02)\end{array}$ & $\begin{array}{l}147 \pm 3 \\
(3.90 \pm 0.09)\end{array}$ & $\begin{array}{l}138 \pm 7 \\
(3.10 \pm 0.02)\end{array}$ \\
\hline \multicolumn{6}{|l|}{ Methylated catechols } \\
\hline 2-Methoxyestrone (2-MeOE1) & $0.040 \pm 0.001$ & $0.025 \pm 0.001$ & $0.030 \pm 0.004$ & $0.030 \pm 0.005$ & $0.030 \pm 0.002$ \\
\hline 2-Methoxyestradiol (2-MeOE2) & $\begin{array}{l}3.7 \pm 0.5 \\
(0.09 \pm 0.01)\end{array}$ & $\begin{array}{l}2.23 \pm 0.08 \\
(0.040 \pm 0.001)\end{array}$ & $\begin{array}{l}2.0 \pm 0.5 \\
(0.04 \pm 0.01)\end{array}$ & $\begin{array}{l}3.9 \pm 0.3 \\
(0.10 \pm 0.01)\end{array}$ & $\begin{array}{l}3.9 \pm 0.1 \\
(0.090 \pm 0.001)\end{array}$ \\
\hline 2-Hydroxyestrone-3-methyl ether (3-MeOE1) & $0.007 \pm 0.002$ & $0.004 \pm 0.001$ & $0.004 \pm 0.001$ & $0.004 \pm 0.002$ & $0.003 \pm 0.001$ \\
\hline \multicolumn{6}{|l|}{ 4-Hydroxylation pathway EM catechols } \\
\hline 4-Hydroxyestrone (4-OHE1) & $2.53 \pm 0.06$ & $3.59 \pm 0.16^{*}$ & $3.7 \pm 0.5^{*}$ & $2.03 \pm 0.04$ & $1.81 \pm 0.13$ \\
\hline \multicolumn{6}{|l|}{ Methylated catechols } \\
\hline 4-Methoxyestrone (4-MeOE1) & $0.09 \pm 0.02$ & $0.040 \pm 0.006$ & $0.040 \pm 0.008$ & $0.070 \pm 0.008$ & $0.080 \pm 0.003$ \\
\hline 4-Methoxyestradiol (4-MeOE2) & $0.36 \pm 0.07$ & $0.200 \pm 0.008$ & $0.190 \pm 0.006$ & $0.260 \pm 0.006$ & $0.26 \pm 0.01$ \\
\hline \multicolumn{6}{|l|}{ 16-Hydroxylation pathway EM } \\
\hline $16 \alpha$-Hydroxyestrone (16 $\alpha$-OHE1) & $0.32 \pm 0.02$ & $0.58 \pm 0.02$ & $0.65 \pm 0.08$ & $0.24 \pm 0.04$ & $0.21 \pm 0.04$ \\
\hline Estriol (E3) & $\begin{array}{l}7 \pm 1 \\
(0.20 \pm 0.03)\end{array}$ & $\begin{array}{l}3.8 \pm 0.3 \\
(0.100 \pm 0.001)\end{array}$ & $\begin{array}{l}6 \pm 1 \\
(0.10 \pm 0.01)\end{array}$ & $\begin{array}{l}4.4 \pm 0.3 \\
(0.10 \pm 0.01)\end{array}$ & $\begin{array}{l}4.3 \pm 0.4 \\
(0.090 \pm 0.001)\end{array}$ \\
\hline 17-Epiestriol (17-epiE3) & $0.040 \pm 0.006$ & $0.020 \pm 0.002$ & $0.030 \pm 0.004$ & $0.030 \pm 0.002$ & $0.030 \pm 0.005$ \\
\hline 16-Ketoestradiol (16-ketoE2) & $0.29 \pm 0.03$ & $0.15 \pm 0.01$ & $0.24 \pm 0.04$ & $0.17 \pm 0.01$ & $0.17 \pm 0.02$ \\
\hline 16-Epiestriol (16-epiE3) & $0.59 \pm 0.09$ & $0.38 \pm 0.02$ & $0.50 \pm 0.07$ & $0.78 \pm 0.09$ & $0.73 \pm 0.03$ \\
\hline Total EM $(\mathrm{M} \pm \mathrm{SEM})$ & $4200 \pm 200$ & $5130 \pm 90^{*}$ & $5600 \pm 200^{*}$ & $3800 \pm 200$ & $4400 \pm 300$ \\
\hline
\end{tabular}

*Significant $(P<0.05)$ difference compared with treatment with E2 alone. Values represent the mean (standard error of the mean) of three independent experiments.

Table 2

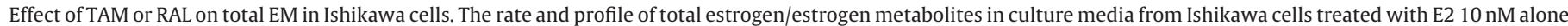

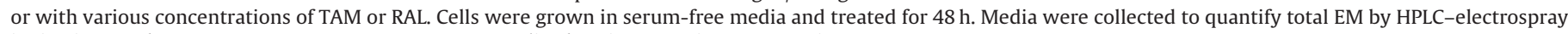
ionization-tandem mass spectrometry. Data were normalized against protein concentration.

\begin{tabular}{|c|c|c|c|c|c|}
\hline \multirow[t]{2}{*}{ Mean } & \multicolumn{5}{|c|}{ pmole/mg protein $/ 48 \mathrm{~h}$ (\% from the total) } \\
\hline & E2 alone $(10 \mathrm{nM})$ & $\mathrm{E} 2+\mathrm{TAM}(100 \mathrm{nM})$ & $\mathrm{E} 2+\mathrm{TAM}(1 \mu \mathrm{M})$ & $\mathrm{E} 2+\mathrm{RAL}(100 \mathrm{nM})$ & $\mathrm{E} 2+\operatorname{RAL}(1 \mu \mathrm{M})$ \\
\hline \multicolumn{6}{|l|}{ Parent estrogens } \\
\hline Estrone (E1) & $\begin{array}{l}870 \pm 30 \\
(15.5 \pm 0.5)\end{array}$ & $\begin{array}{l}800 \pm 100 \\
(11 \pm 2)\end{array}$ & $\begin{array}{l}900 \pm 100 \\
(12 \pm 2)\end{array}$ & $\begin{array}{l}900 \pm 100 \\
(17 \pm 3)\end{array}$ & $\begin{array}{l}1000 \pm 200 \\
(19 \pm 4)\end{array}$ \\
\hline Estradiol (E2) & $\begin{array}{l}4600 \pm 200 \\
(83 \pm 4)\end{array}$ & $\begin{array}{l}6700 \pm 400 \\
(89 \pm 3)\end{array}$ & $\begin{array}{l}6900 \pm 200 \\
(88 \pm 3)\end{array}$ & $\begin{array}{l}4500 \pm 200 \\
(81 \pm 4)\end{array}$ & $\begin{array}{l}4100 \pm 100 \\
(80 \pm 4)\end{array}$ \\
\hline \multicolumn{6}{|l|}{ 2-Hydroxylation pathway EM catechols } \\
\hline 2-Hydroxyestrone (2-OHE1) & $1.0 \pm 0.2$ & $0.79 \pm 0.05$ & $0.61 \pm 0.08$ & $2 \pm 1$ & $0.86 \pm 0.09$ \\
\hline 2-Hydroxyestradiol (2-OHE2) & $\begin{array}{l}46 \pm 1 \\
(0.83 \pm 0.02)\end{array}$ & $\begin{array}{l}39 \pm 4 \\
(0.50 \pm 0.05)\end{array}$ & $\begin{array}{l}34 \pm 3 \\
(0.43 \pm 0.04)\end{array}$ & $\begin{array}{l}50 \pm 20 \\
(2.3 \pm 0.3)\end{array}$ & $\begin{array}{l}44 \pm 4 \\
(0.85 \pm 0.07)\end{array}$ \\
\hline \multicolumn{6}{|l|}{ Methylated catechols } \\
\hline 2-Methoxyestrone (2-MeOE1) & $0.006 \pm 0.002$ & $0.015 \pm 0.003$ & $0.008 \pm 0.008$ & $0.05 \pm 0.02$ & $0.006 \pm 0.002$ \\
\hline 2-Methoxyestradiol (2-MeOE2) & $\begin{array}{l}10.0 \pm 0.8 \\
(0.18 \pm 0.02)\end{array}$ & $\begin{array}{l}5.3 \pm 0.8 \\
(0.07 \pm 0.01)\end{array}$ & $\begin{array}{l}4.1 \pm 0.5 \\
(0.050 \pm 0.006)\end{array}$ & $\begin{array}{l}8.7 \pm 0.9 \\
(0.16 \pm 0.02)\end{array}$ & $\begin{array}{l}11.1 \pm 0.4 \\
(0.200 \pm 0.006)\end{array}$ \\
\hline 2-Hydroxyestrone-3-methyl ether (3-MeOE1) & $0.0007 \pm 0.0001$ & $0.0012 \pm 0.0003$ & $0.001 \pm 0.001$ & $0.009 \pm 0.006$ & $0.003 \pm 0.008$ \\
\hline \multicolumn{6}{|l|}{ 4-Hydroxylation pathway EM catechols } \\
\hline 4-Hydroxyestrone (4-OHE1) & $1.0 \pm 0.3$ & $2.3 \pm 0.3$ & $9 \pm 1$ & $1.1 \pm 0.1$ & $1.22 \pm 0.01$ \\
\hline \multicolumn{6}{|l|}{ Methylated catechols } \\
\hline 4-Methoxyestrone (4-MeOE1) & $0.11 \pm 0.03$ & $0.07 \pm 0.01$ & $0.08 \pm 0.01$ & $0.29 \pm 0.09$ & $0.17 \pm 0.03$ \\
\hline 4-Methoxyestradiol (4-MeOE2) & $0.28 \pm 0.01$ & $0.18 \pm 0.01$ & $0.140 \pm 0.002$ & $0.290 \pm 0.004$ & $0.310 \pm 0.002$ \\
\hline \multicolumn{6}{|l|}{ 16-Hydroxylation pathway EM } \\
\hline $16 \alpha$-Hydroxyestrone (16 $\alpha$-OHE1) & $0.17 \pm 0.02$ & $0.32 \pm 0.03$ & $0.288 \pm 0.002$ & $0.17 \pm 0.01$ & $0.19 \pm 0.04$ \\
\hline Estriol (E3) & $\begin{array}{l}1.38 \pm 0.02 \\
(0.0250 \pm 0.0003)\end{array}$ & $\begin{array}{l}1.461 \pm 0.006 \\
(0.0220 \pm 0.0001)\end{array}$ & $\begin{array}{l}1.743 \pm 0.002 \\
(0.02300 \pm 0.00001)\end{array}$ & $\begin{array}{l}4.7 \pm 2.2 \\
(0.08 \pm 0.04)\end{array}$ & $\begin{array}{l}1.917 \pm 0.002 \\
(0.03700 \pm 0.00003)\end{array}$ \\
\hline 17-Epiestriol (17-epiE3) & $0.027 \pm 0.007$ & $0.037 \pm 0.006$ & $0.027 \pm 0.004$ & $0.08 \pm 0.03$ & $0.024 \pm 0.003$ \\
\hline 16-Ketoestradiol (16-ketoE2) & $0.142 \pm 0.005$ & $0.24 \pm 0.03$ & $0.24 \pm 0.03$ & $0.5 \pm 0.2$ & $0.19 \pm 0.04$ \\
\hline 16-Epiestriol (16-epiE3) & $0.25 \pm 0.02$ & $0.35 \pm 0.05$ & $0.38 \pm 0.01$ & $0.8 \pm 0.3$ & $0.30 \pm 0.06$ \\
\hline Total EM $(\mathrm{M} \pm \mathrm{SEM})$ & $5600 \pm 200$ & $7700 \pm 400$ & $7900 \pm 300^{*}$ & $5600 \pm 400$ & $5200 \pm 400$ \\
\hline
\end{tabular}

*Significant $(P<0.05)$ difference compared with treatment with E2 alone. Values represent the mean (standard error of the mean) of three independent experiments.

of total EM. However, treatment with TAM (100 nM or $1 \mu \mathrm{M})$ significantly decreased the rate of 2-OHE2 formation to $1.8 \pm 0.02 \%$ and $1.3 \pm 0.02 \%$ of total EM, respectively. In contrast, in EM cells treated with E2 and 100 or $1 \mu \mathrm{M}$ of RAL, there were no significant changes in the rate of 2 -OHE2 formation $(3.9 \pm 0.09 \%$ and $3.1 \pm 0.017 \%$ of total EM, respectively). Our data also suggested that Ishikawa cells metabolize E2 into 2-OHE2 at a lower rate ( $<1 \%$ of total EM) in comparison to EM1 cells. However, TAM exhibited a subtle decrease on 


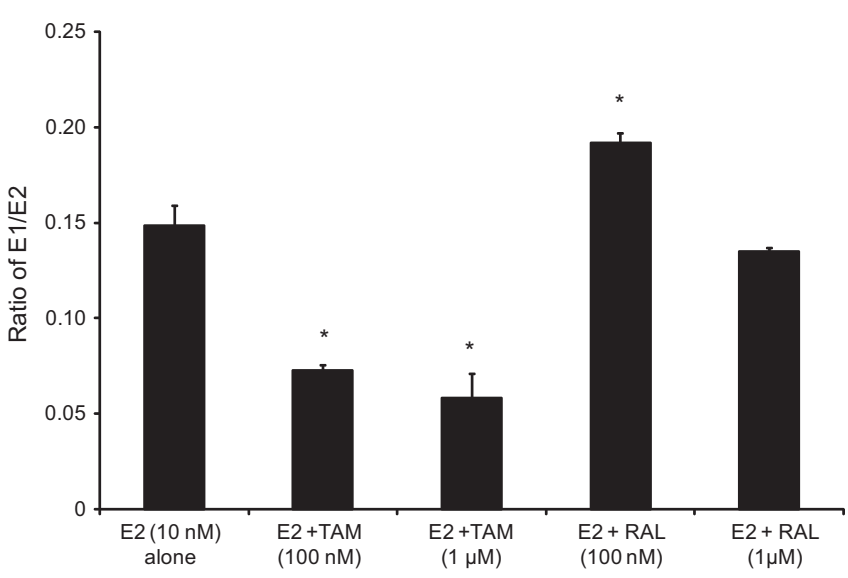

Fig. 1. The E1/E2 ratio was significantly lower compared with cells treated with E2 alone in EM1 cells treated with E2 plus TAM. The ratio of E1/E2 ratio in culture media from EM1 cells treated with E2 $10 \mathrm{nM}$ alone or with various concentrations of TAM or RAL. Cells were grown in serum-free media and treated for $48 \mathrm{~h}$. Media were collected to quantify the E1/E2 ratio by HPLC-electrospray ionization-tandem mass spectrometry. Data were normalized against protein concentration. *Significant $(P<0.05)$ difference compared with treatment with E2 alone. Values represent the mean; bars represent the standard error of the mean.

the formation rate of 2-OHE2, while RAL tended to increase the formation rate of 2-OHE2 significantly at the $100 \mathrm{nM}$ concentration, compared with Ishikawa cells treated with E2 alone (Table 2).

The rate of 2-OHE1 formation was lower compared with the formation rate of 2-OHE2 in both EM1 and Ishikawa cells (Tables 1 and 2). Our data confirmed that in EM1 cells, TAM significantly reduced the rate of 2-OHE1 formation compared to cells treated with E2 alone, while RAL had no significant effect (Table 1).

$16 \alpha$-Hydroxyestrone (16 $\alpha$-OHE1) has strong hormonal and tumor-promoting activities; thus, we assessed the rate of $16 \alpha-$ OHE1 in E2- and TAM-treated cells. Our data demonstrate that the formation of $16 \alpha-$ OHE1 was significantly higher in TAM-treated cells compared to cells treated with E2 alone in both EM1 and Ishikawa cells. In contrast to TAM, RAL did not induce significant change in the rate of $16 \alpha-$ OHE1 formation (Tables 1 and 2 ).

4-Hydroxyestrone is a tumor-promoting estrogen metabolite that induces oxidative stress, microsatellite instability, and neoplastic transformation in EM1 cells. Therefore, we assessed the effect of TAM or RAL on E2 metabolism into 4-OHE1. Our results indicate that TAM significantly enhanced E2 metabolism into 4OHE1 in EM1 cells. However, RAL did not have a profound effect on the formation rate of 4-OHE1 (Table 1 ). A comparable pattern of TAM or RAL effects on 4-OHE1 formation rate was observed in Ishikawa cells (Table 2).

The rate of formation of methoxyestrogens is critical for estrogen carcinogenesis. We analyzed the effects of TAM or RAL on the rate of methoxyestrogen formation. 2-methoxyestradiol (2$\mathrm{MeOE} 2$ ) is an anticancer and antiangiogenic agent. As illustrated in Tables 1 and 2, 2-MeOE2 is the major methylated catechol estrogen detected and to a lesser extent, 4-methoxyestadiol (4-MeOE2), 4-methoxyestrone (4-MeOE1), and 2-methoxyestrone (2-MeOE1), in decreasing rates. Compared with E2-treatment alone, TAM markedly decreased the rate of methoxyestrogens formation, in both EM1 and Ishikawa cells (Tables 1 and 2). On the other hand, RAL did not change methoxyestrogens formation rates in either cell line (Tables 1 and 2).

\subsection{Effect of TAM or RAL on the ratios of specific estrogen metabolites in endometrial cells}

To further assess the effects of TAM and RAL on estrogen metabolism, we derived the ratios for E1/E2, 2-OHE1/16 $\alpha$-OHE1, and 2-MeOE2/4-OHE1, which are the most commonly used predic-

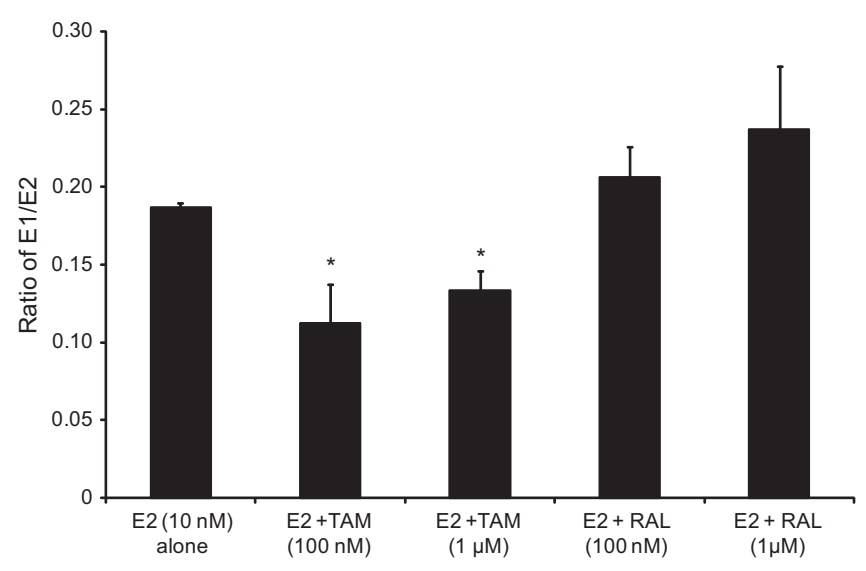

Fig. 2. The E1/E2 ratio was significantly lower compared with cells treated with E2 alone in Ishikawa cells treated with E2 plus TAM. The ratio of E1/E2 ratio in culture media from Ishikawa cells treated with E2 $10 \mathrm{nM}$ alone or with various concentrations of TAM or RAL as previously described. *Significant $(P<0.05)$ difference compared with treatment with $\mathrm{E} 2$ alone. Values represent the mean; bars represent the standard error of the mean.

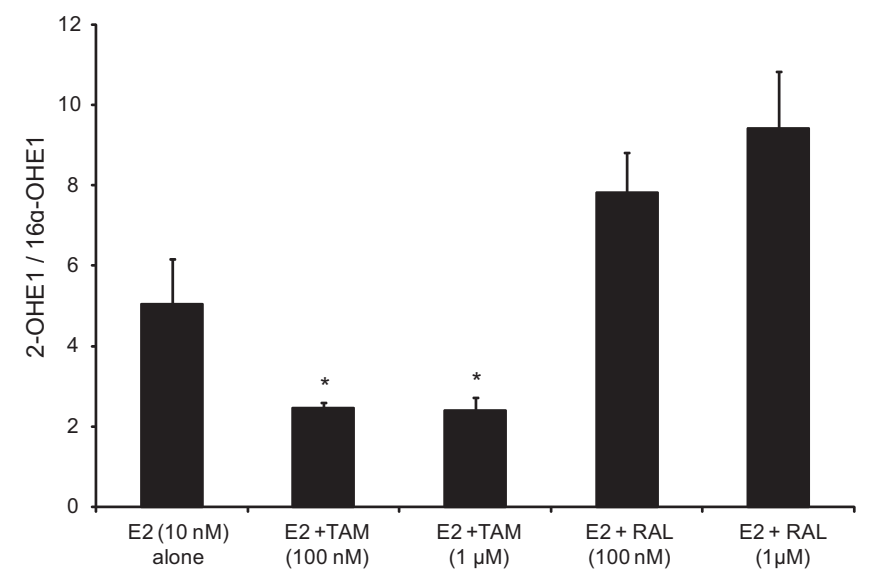

Fig. 3. Treatment with E2 and TAM significantly decreased the 2-OHE1/16 $\alpha$-OHE1 ratio compared with the treatment with E2 alone in EM1 cells; E2 and RAL increased this ratio. The ratio of 2-OHE1/16 $\alpha$ - OHE1 ratio in culture media from EM1 cells treated with E2 $10 \mathrm{nM}$ alone or with various concentrations of TAM or RAL as previously described. *Significant $(P<0.05)$ difference compared with treatment with E2 alone. Values represent the mean; bars represent the standard error of the mean.

tors for cancer risk. As indicated in Fig. 1, TAM shifted the E1/E2 equilibrium towards the formation of more E2. Thus, in EM1 cells treated with E2 plus TAM, the E1/E2 ratio was significantly lower compared with cells treated with E2 alone. However, in cells treated with E2 and RAL, the E1/E2 ratio increased compared with E2-onlytreated cells. Similarly, in Ishikawa cells, the profile of E1/E2 ratios following treatment with TAM or RAL was comparable to that in EM1 cells (Fig. 2).

Our data indicate that in EM1 and Ishikawa cells, treatment with E2 and TAM significantly decreased the 2-OHE1/16 $\alpha$-OHE1 ratio compared with treatment with E2 alone, and, in contrast, E2 and RAL increased this ratio (Figs. 3 and 4).

We evaluated the 2-MeOE2/4-OHE1 ratios resulting from treating endometrial cells with E2 alone or in combination with TAM or RAL in EM1 and Ishikawa cells. Our data suggest that while treatment with TAM significantly decreased the 2-MeOE2/4-OHE1 ratio in both cell lines, treatment with RAL increased this ratio significantly in EM1 cells (Figs. 5 and 6). 


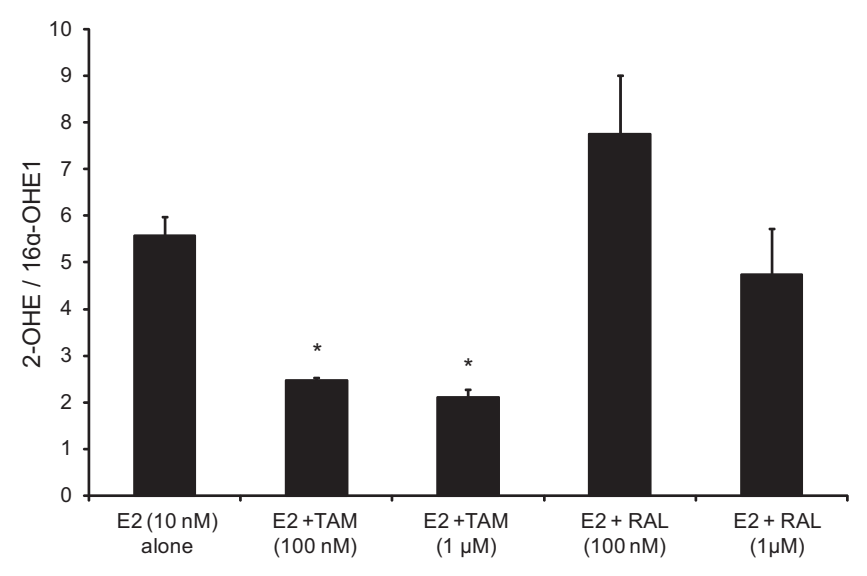

Fig. 4. Treatment with E2 and TAM significantly decreased the 2-OHE1/16 $\alpha$-OHE1 ratio compared with the treatment with $\mathrm{E} 2$ alone in Ishikawa cells; RAL increased this ratio. The ratio of 2-OHE1/16 $\alpha$-OHE1 ratio in culture media from Ishikawa cells treated with E2 $10 \mathrm{nM}$ alone or with various concentrations of TAM or RAL as previously described. *Significant $(P<0.05)$ difference compared with treatment with E2 alone. Values represent the mean; bars represent the standard error of the mean.

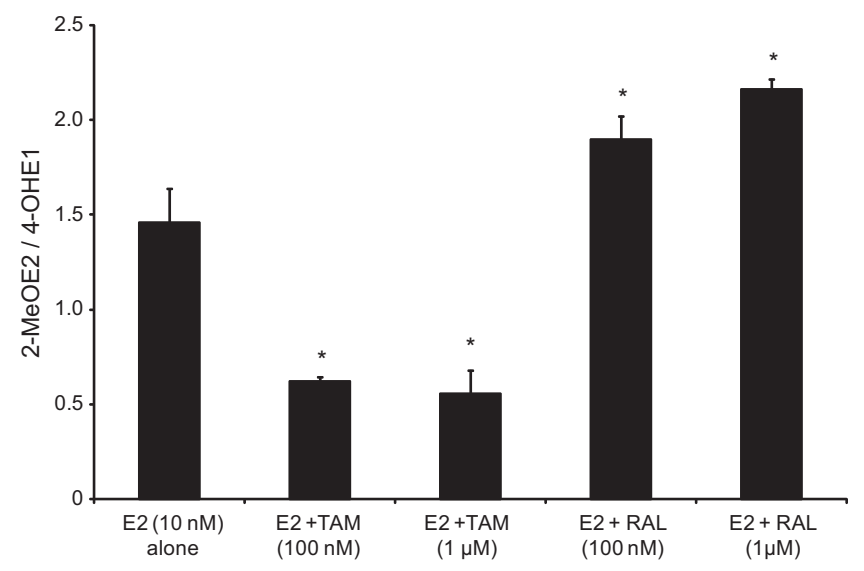

Fig. 5. Treatment with TAM significantly decreased the 2-MeOE2/4-OHE1 ratio in EM1 cells; treatment with RAL significantly increased this ratio. The ratio of $2 \mathrm{ME} / 4$ OHE1 ratio in culture media from EM1 cells treated with E2 $10 \mathrm{nM}$ alone or with various concentrations of TAM or RAL as previously described. *Significant $(P<0.05)$ difference compared with treatment with E2 alone. Values represent the mean; bars represent the standard error of the mean.

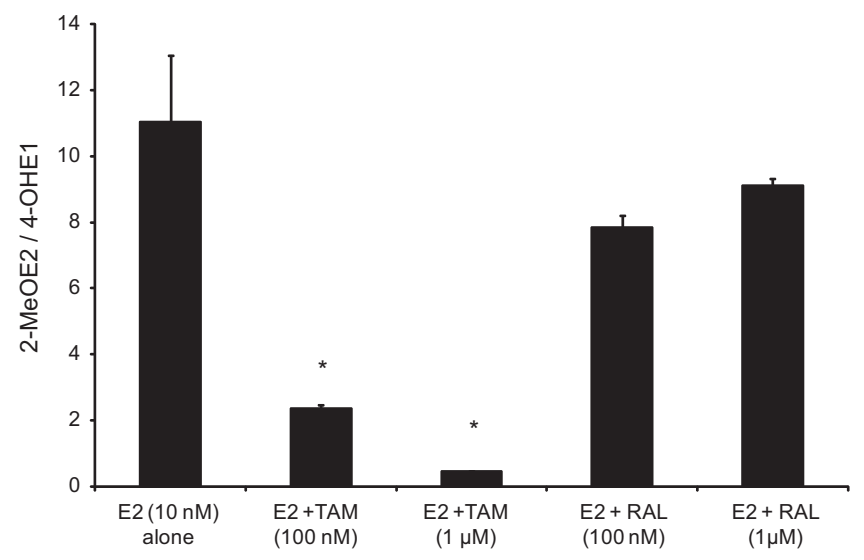

Fig. 6. Treatment with TAM significantly decreased the 2-MeOE2/4-OHE1 ratio in Ishikawa cells. The ratio of 2ME/4-OHE1 ratio in culture media from Ishikawa cells treated with E2 $10 \mathrm{nM}$ alone or with various concentrations of TAM or RAL as previously described. *Significant $(P<0.05)$ difference compared with treatment with E2 alone. Values represent the mean; bars represent the standard error of the mean.

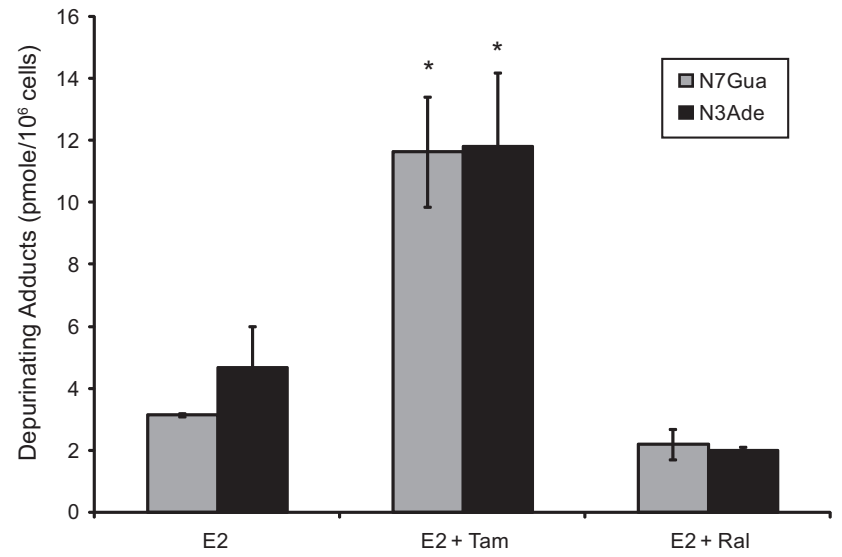

Fig. 7. TAM significantly increased the levels of depurinating DNA adducts in EM1 cells. The levels of DNA adducts (4-OHE1 [2]-1-N7Guanine and 4-OHE1 [2]-1-N3 Adenine), were determined in culture media from EM-1 endometrial cells treated with either E2 $(10 \mathrm{nM})$ alone or in combination with either TAM $(1 \mu \mathrm{M})$ or RAL $(1 \mu \mathrm{M})$ by ultraperformance liquid chromatography/tandem mass spectrometry (UPLC-MS/MS)

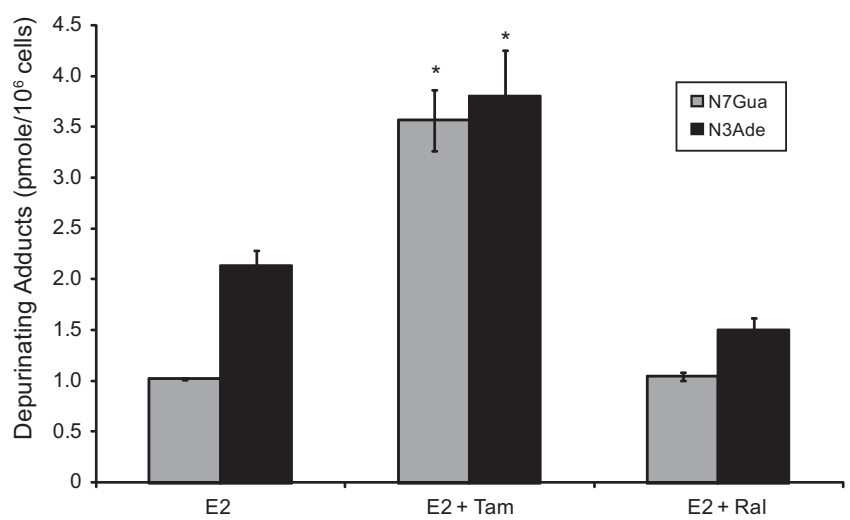

Fig. 8. TAM significantly increased the levels of depurinating DNA adducts in Ishikawa cells. The levels of DNA adducts (4-OHE1 [2]-1-N7Guanine and 4-OHE1 [2]-1-N3 Adenine) were determined in culture media from Ishikawa endometrial cells treated with either E2 $(10 \mathrm{nM})$ alone or in combination with either TAM $(1 \mu \mathrm{M})$ or RAL $(1 \mu \mathrm{M})$ by ultraperformance liquid chromatography/tandem mass spectrometry (UPLC-MS/MS).

\subsection{Effect of TAM or RAL on estrogen-induced depurinating DNA adducts}

To investigate the implications of the possible effects of TAM or RAL on E2 metabolism and the formation of depurinating DNA adducts, the levels of DNA adducts (4-OHE1 [2]-1-N7Guanine and 4-OHE1 [2]-1-N3 Adenine) were determined in culture media from endometrial cells treated with either E2 $(10 \mathrm{nM})$ alone or in combination with either TAM $(1 \mu \mathrm{M})$ or RAL $(1 \mu \mathrm{M})$ by ultraperformance liquid chromatography/tandem mass spectrometry (UPLC-MS/MS). Our results indicated that in EM1 and Ishikawa cells, TAM significantly increased the levels of the depurinating DNA adducts 4-OHE1 [2]-1-N7Guanine and 4-OHE1 [2]-1-N3 Adenine compared with treatment with E2 alone. RAL $(1 \mu \mathrm{M})$ did not significantly change the level of E2-induced DNA adducts (Figs. 7 and 8).

\subsection{Effect of TAM or RAL on estrogen-metabolizing genes expression in endometrial cells}

To understand the underlying mechanism of the differential pattern of estrogen metabolites and the rate of estrogen-induced 


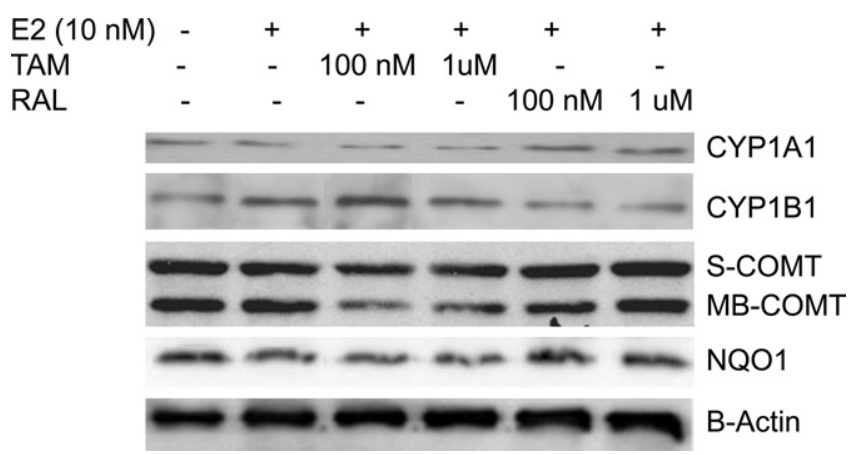

Fig. 9. Expression of CYP1A1, CYP1B1, S-COMT, MB-COMT, NQO1, and $\beta$-actin in EM1 cells. Cells were treated with E2 alone or in combination with various concentrations of TAM or RAL. Total cell lysates, nuclear fraction, and cytoplasmic fraction were prepared as described in Section 2. CYP1A1, CYP1B1, S-COMT, MB-COMT, NQ01, and $\beta$-actin expression were determined using Western blot analysis. The level of CYP1B1 was increased by E2 and further increased by addition of TAM. The expression of CYP1A1 was decreased by E2 and further decreased by addition of TAM. E2 alone or in combination with TAM resulted in a marked reduction in COMT and NQO1 expression compared with the control.

adducts formation between TAM- and RAL-treated endometrial cells, we assessed the effect of TAM or RAL on the expression of key genes involved in estrogen metabolism. We studied the effect of E2 with and without TAM or RAL on the expression of CYP1A1 and CYP1B1 in EM1. As indicated in Fig. 9, the expression of CYP1B1 was induced by treatment with E2. The level of CYP1B1 was further increased by TAM (Fig. 9). In contrast to TAM, RAL did not affect the CYP1B1 expression in EM1. Regarding the CYP1A1 protein expression, our data suggest that E2 downregulated CYP1A1 expression compared with vehicle-treated control. The downregulation of CYP1A1 was even more pronounced by co-treatment with TAM. In contrast, RAL notably increased the CYP1A1 expression in EM1 cells (Fig. 9).

In extrahepatic tissues, including endometrial tissues, the catechol estrogens are detoxified primarily by $\mathrm{O}$-methylation catalyzed by catechol-O-methyltransferase (COMT) and $\mathrm{NAD}(\mathrm{P}) \mathrm{H}$-quinone oxidoreductase (NQO1). These detoxification reactions impede the easy oxidation of catechol estrogens to corresponding genotoxic metabolites and prevent the formation of estrogen depurinating DNA adducts. Accordingly, we also investigated the expression of COMT and NQO1 enzymes in endometrial cells treated with E2 alone or in combination with TAM or RAL. Our data revealed that E2 alone or in combination with TAM resulted in a marked reduction in COMT and NQO1 expression compared with the vehicle-treated control. The reduction in COMT and NQO1 expression was more evident in cells treated with E2 and TAM compared with cells treated with E2 alone. On the other hand, in E2 plus RAL-treated cells, there was a slight increase in COMT and NQO1 expression compared with cells treated with E2 alone (Fig. 9). A similar profile of

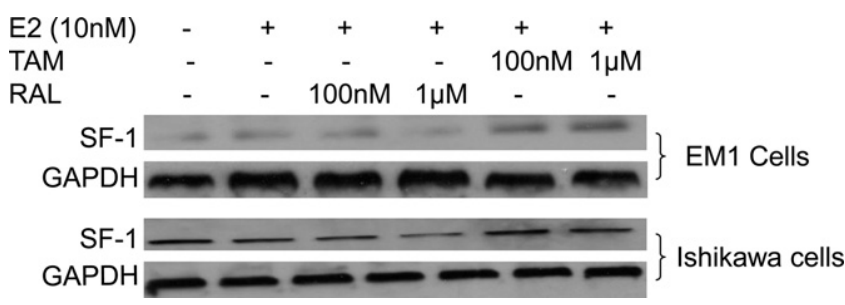

Fig. 10. Expression of SF-1 and GAPDH in EM1 cells and Ishikawa cells. Cells were treated with E2 alone or in combination with various concentrations of TAM or RAL. Total cell lysates, nuclear fraction, and cytoplasmic fraction were prepared as described in the materials and methods section. SF-1 and GAPDH expression was determined using Western blot analysis. The level of SF-1 was increased by addition of TAM in EM1 and Ishikawa cells. estrogen-metabolizing gene expression was observed in Ishikawa cells.

GPR30 estrogen receptor (GPER) has been shown to activate the steroidogenic factor 1 (SF-1), which is a transcription factor that induces aromatase expression in endometrial cells. Therefore, we investigated the effect of TAM and RAL on the expression of SF-1 in EM1 and Ishikawa cells. Our results show that TAM induced the expression of SF-1 in both EM1 and Ishikawa cells (Fig. 10).

\section{Discussion}

Although, both TAM and RAL are members of the SERM class of drugs, they have distinctive effects on endometrium, and the underlying mechanisms of their disparate effects are not fully understood. Understanding of the relevant pathways involved in TAM-associated EC is a matter of great importance to allow more accurate assessment of the risk to women receiving TAM treatment and, more importantly, to develop chemoprevention approaches. It is postulated that TAM-associated EC is attributed to the hormonal effect of TAM on endometrial tissues and its potential to form DNA adducts $[6-8,5]$. However, this mechanism has been disputed, and many studies even suggest that initiation of EC by TAM does not involve the formation of TAM-DNA adducts $[15,14,13]$. This is consistent with the finding that TAM-DNA adducts cannot be detected in endometrial DNA from women who had undergone TAM therapy for extended period of time, even with the use of specific detection techniques, such as HPLC-electrospray ionization-tandem mass spectrometry (HPLC-ES-MS/MS) [17,15,14,13,16]. Although, TAMadduct formation may occur at a very low level in a proportion of patients, the significance of TAM-DNA adducts in the development of EC is unclear. These mixed results and the apparent inconsistencies of the data regarding TAM-DNA adducts in human endometrial tissues suggest that there may be an alternative or complementary mechanism underlying TAM-induced EC. Increasing experimental evidence suggests that TAM-induced EC may proceed as a consequence of TAM-induced changes in gene expression in endometrial epithelial cells [32,33]. Indeed, substantial evidence suggests a potential role for TAM in regulating the expression of genes involved in estrogen biosynthesis and metabolism $[25,22-24,26,27]$. Thus, this explains our novel approach aimed at investigating the hypothesis that TAM induces EC by altering the rate and pattern of estrogen metabolism/metabolites (EM). In addition, the disparate effects of TAM and RAL in EC risk are attributed, at least in part, to their differential effects on estrogen metabolism.

It is widely believed that estrogen-induced cancers are attributed, at least in part, to certain estrogen metabolites, which have profound consequences on the biological, as well as the pathological, effects of estrogen. Indeed, there is evidence that in situ formation of estrogen metabolites can have biological properties, even at very low concentrations, which can exceed the effects of their parent substance by many fold [34,35]. It has been suggested that many of the effects of estrogen may not be caused by estradiol per se but may result from the formation of active estrogen metabolites that function as local mediators or activate their own unique receptors or effectors [36]. 17 $\beta$-Estradiol (E2) is metabolized into a variety of compounds that are different in their hormonal and carcinogenic potentials. 4-hydroxyestradiol and $16 \alpha$-hydroxyestrone are tumor promoting, whereas the 2hydroxylation pathway demonstrates weak estrogenic or even antiestrogenic effects [37,36]. In addition, 2-methoxyestradiol (2-MeOE2) is an anticancer and antiangiogenic agent [38]. We previously demonstrated that E2 and 4-hydroxyestradiol (4-OHE2) induce oxidative stress, microsatellite instabilities, and neoplastic transformation of human endometrial glandular epithelial cells, whereas 2-hydroxyestradiol (2-OHE2) does not cause cellular 
transformation or genomic instabilities [21]. Thus, the imbalanced expression of estrogen-metabolizing genes, the profile of estrogen metabolites, and the predisposition of the individual metabolite pattern might be crucial for many physiological and pathological conditions in the endometrium.

One of the interesting findings in our study is that the total EM was significantly higher in conditioned media from endometrial cells treated with E2 plus TAM compared with cells treated with E2 alone. By contrast, RAL treatment did not result in any significant change in EM. Of note, the stability of estrogen metabolites detected in this manner has been verified in a separate study [39]. This TAMassociated increase in total EM could suggest that TAM increased the local estrogen biosynthesis in endometrial cells. TAM-induced increase in total EM could be explained in light of the finding that TAM stimulates the GPR30 estrogen receptor (GPER), which in turn, activates the steroidogenic factor 1 (SF-1), which is a transcription factor that induces aromatase expression in endometrial cells [40-42,22].

The interconversion of weakly active estrone (E1) into highly potent estradiol (E2) and their relative abundance dictate the estrogenic milieu. A decrease in the E1/E2 ratio is conducive for the development of EC. Our results suggest that TAM significantly decreased the E1/E2 ratio due to a decrease in the disposition of estrogen as E1 with a concomitant increase in E2 concentration. This alteration in E1/E2 ratio could be explained in light of the experimental evidence that TAM modulates the expression of hydroxysteroid (17beta) dehydrogenase 1 (HSD17B1), an enzyme that efficiently catalyzes the conversion of E1 into E2 [23,43,44].

Another important finding in our study is that, in contrast to RAL, TAM alters the 2 - and the $16 \alpha$-hydroxylation pathways of estrogen metabolism in endometrial cells, which results in TAM decreasing the 2 -OHE1/16 $\alpha$-OHE1 ratio. The $16 \alpha$-OHE1 metabolite is a potent estrogenic molecule that activates estrogen receptors, whereas the 2-OHE1 metabolite has very little estrogen receptor binding affinity $(<0.1 \%$ compared to E2) [45]. Observational trials have demonstrated that a decreased ratio of 2- to 16-alpha-hydroxyoestrone is associated with EC risk [46]. Thus, it is anticipated that factors, which decrease the 2-OHE1/16 $\alpha$-OHE1 ratio, such as TAM, could induce EC. On the other hand, RAL, which exerts a modest increase in 2-OHE1/16 $\alpha$-OHE1 ratio, does not increase, and, in fact, decreases the risk for EC [4]. Also, our data indicate that treatment with TAM is associated with increased levels of 4-OHE1, one of the most potent carcinogenic estrogen metabolites [47]. Interestingly, this is accompanied by a significant decrease in the anticarcinogenic estrogen metabolite 2-methoxyestradiol. Thus, it would be anticipated that the collective effect of TAM on EM can enhance the estrogenic milieu and create a metabolic microenvironment conducive for the development of EC. This profile of estrogen metabolites is a result of imbalances in the relative expression of critical enzymes involved in estrogen activation/deactivation in the endometrial EC.

We then investigated the biological consequences of the TAMor RAL-derived estrogen metabolism/metabolites by measuring the formation of estrogen-DNA adducts. In addition to its estrogenic activity on cell proliferation, 4-OH-E2 undergoes redox cycling during which reactive oxygen species, such as superoxide anion and the chemically reactive estrogen semiquinone and quinone intermediates, are produced. These genotoxic estrogen metabolites react with DNA to form depurinating DNA-adducts. Indeed, our study demonstrated that treatment with TAM is associated with a significant increase in estrogen-induced depurinating adducts. It is likely that the increase in estrogen-depurinating adducts resulted from the increased level of 4-OHE1 and downregulation of the detoxification enzymes COMT and NQO1. Depurinating adducts can induce mutations and genomic instabilities in critical genes such as the K-ras oncogene and tumor suppressor genes TP53 and
PTEN. These events can cause phenotypical changes indicative of neoplastic transformation in endometrial tissues [21].

To understand why TAM or RAL alters the rate and pattern of estrogen metabolites, we explored the effect of TAM or RAL on the expression of key genes involved in estrogen metabolism. Our data indicate that TAM increases the expression level of CYP1B1, while it decreases CYP1A1 expression. In contrast to TAM, RAL did not affect CYP1B1 expression but notably increases CYP1A1 expression. These effects were associated with a concomitant effect on the expression of detoxification enzymes COMT and NQO1. TAM reduces COMT and NQO1 expression while RAL causes a slight increase in COMT and NQO1 expression. In previous studies, it was shown that CYP1A1 and CYP1B1 gene expression, which are responsible for the metabolism of estrogen into 2-OHE1 and 4-OHE1, respectively, can be regulated by estrogen receptors, which are activated by TAM or RAL in endometrial cells $[38,48]$. Similarly, CYP3A4, which is responsible for the oxidation of estrogen into $16 \alpha-\mathrm{OHE} 1$, is induced by TAM $[49,50]$. Similarly, several reports point to the ability of SERMs to modulate the expression of the estrogendetoxification enzymes [25,51]. The observation that TAM and RAL differentially regulate the expression of genes involved in estrogen metabolism is consistent with previous studies showing differences of TAM and RAL on gene expression [52]. These differences can be explained based on the mounting evidence that TAM and RAL have different affinities for different subtypes of estrogen receptors. Furthermore, different ligand-receptor complexes are capable of regulating gene expression through different coregulator recruitment in a gene-specific manner [32,53]. In addition, previous studies have demonstrated that the transcriptional activity of TAM is mediated by its interaction with target gene promoters that harbor either a classical ERE, a half ERE site, or EpRE [54,55]. Thus, it is reasonable to speculate that owing to their different conformations, different coactivator associations, and differential affinity to other receptors, TAM and RAL possess different affinities for different gene promoters that would explain differences in gene regulation, including estrogen metabolizing genes.

\section{Conclusion}

Our novel data suggest a new potential mechanism for TAM-associated EC and provide a plausible explanation for the differential effects of TAM and RAL on EC risk. Our study suggests that TAM-induced imbalanced expression of estrogen-metabolizing enzymes and altered disposition of estrogen metabolites can explain, at least in part, the mechanism for TAM-induced EC. TAM and RAL have different effects on the expression of E2 metabolizing genes, estrogen metabolites, and on estrogen-DNA adduct formation, which may play a role in their different risk profiles for EC. However, our results do not exclude the possibility that other asyet-undetermined factors may contribute to the differential effect of TAM and RAL on the endometrium as well as the carcinogenic effect of TAM.

\section{Acknowledgments}

For editorial and graphic assistance, we thank Ob/Gyn Publications director and staff: R.G. McConnell, LeAnne Garcia, and Alan Sheffield.

\section{References}

[1] I. Cohen, Endometrial pathologies associated with postmenopausal tamoxifen treatment, Gynecol. Oncol. 94 (2004) 256-266.

[2] P. Neven, I. Vergote, Controversies regarding tamoxifen and uterine carcinoma, Curr. Opin. Obstet. Gynecol. 10 (1998) 9-14 
[3] B.M. Slomovitz, C.C. Sun, P.T. Ramirez, D.C. Bodurka, P. Diaz, K.H. Lu, Does tamoxifen use affect prognosis in breast cancer patients who develop endometrial cancer? Obstet. Gynecol. 104 (2004) 255-260.

[4] A. DeMichele, A.B. Troxel, J.A. Berlin, A.L. Weber, G.R. Bunin, E. Turzo, R. Schinnar, D. Burgh, M. Berlin, S.C. Rubin, T.R. Rebbeck, B.L. Strom, Impact of raloxifene or tamoxifen use on endometrial cancer risk: a population-based case-control study, J. Clin. Oncol. 26 (2008) 4151-4159.

[5] K. Hemminki, H. Rajaniemi, B. Lindahl, B. Moberger, Tamoxifen-induced DNA adducts in endometrial samples from breast cancer patients, Cancer Res. 56 (1996) 4374-4377.

[6] S. Shibutani, N. Suzuki, I. Terashima, S.M. Sugarman, A.P. Grollman, M.L. Pearl, Tamoxifen-DNA adducts detected in the endometrium of women treated with tamoxifen, Chem. Res. Toxicol. 12 (1999) 646-653.

[7] S. Shibutani, A. Ravindernath, N. Suzuki, I. Terashima, S.M. Sugarman, A.P. Grollman, M.L. Pearl, Identification of tamoxifen-DNA adducts in the endometrium of women treated with tamoxifen, Carcinogenesis 21 (2000) 1461-1467.

[8] A. Umemoto, Y. Monden, C.X. Lin, M. bdul-Momen, Y. Ueyama, K. Komaki, Y.R. Laxmi, S. Shibutani, Determination of tamoxifen-DNA adducts in leukocytes from breast cancer patients treated with tamoxifen, Chem. Res. Toxicol. 17 (2004) 1577-1583.

[9] S.Y. Kim, N. Suzuki, Y.R. Laxmi, S. Shibutani, Genotoxic mechanism of tamoxifen in developing endometrial cancer, Drug Metab. Rev. 36 (2004) 199-218.

[10] K. Brown, Is tamoxifen a genotoxic carcinogen in women? Mutagenesis 24 (2009) 391-404.

[11] A. Besaratinia, G.P. Pfeifer, Investigating DNA adduct-targeted mutagenicity of tamoxifen: preferential formation of tamoxifen-DNA adducts in the human p53 gene in SV40 immortalized hepatocytes but not endometrial carcinoma cells, Biochemistry 44 (2005) 8418-8427.

[12] E. Liapis, K.I. McLuckie, P.D. Lewis, P.B. Farmer, K. Brown, Mutagenicity of tamoxifen DNA adducts in human endometrial cells and in silico prediction of p53 mutation hotspots, Nucleic Acids Res. 36 (2008) 5933-5945.

[13] P.L. Carmichael, S. Sardar, N. Crooks, P. Neven, H.I. Van, A. Ugwumadu, T. Bourne, E. Tomas, P. Hellberg, A.J. Hewer, D.H. Phillips, Lack of evidence from HPLC 32P-post-labelling for tamoxifen-DNA adducts in the human endometrium, Carcinogenesis 20 (1999) 339-342.

[14] P.L. Carmichael, A.H. Ugwumadu, P. Neven, A.J. Hewer, G.K. Poon, D.H. Phillips, Lack of genotoxicity of tamoxifen in human endometrium, Cancer Res. 56 (1996) 1475-1479.

[15] F.A. Beland, M.I. Churchwell, D.R Doerge, D.R. Parkin, D. Malejka-Giganti, A. Hewer, D.H. Phillips, P.L. Carmichael, C.G. Gamboa da, M.M. Marques, Electrospray ionization-tandem mass spectrometry and 32P-postlabeling analyses of tamoxifen-DNA adducts in humans, J. Natl. Cancer Inst. 96 (2004) 1099-1104.

[16] D.H. Phillips, A. Hewer, P.L. Grover, G.K. Poon, P.L. Carmichael, Tamoxifen does not form detectable DNA adducts in white blood cells of breast cancer patients Carcinogenesis 17 (1996) 1149-1152.

[17] H. Bartsch, D.H. Phillips, J. Nair, A. Hewer, G. Meyberg-Solomeyer, E.M. Grischke, Lack of evidence for tamoxifen- and toremifene-DNA adducts in lymphocytes of treated patients, Carcinogenesis 21 (2000) 845-847.

[18] L. Morales, D. Timmerman, P. Neven, M.L. Konstantinovic, A. Carbonez, H.S. Van, L. Ameye, C. Weltens, M.R. Christiaens, I. Vergote, R. Paridaens, Third generation aromatase inhibitors may prevent endometrial growth and reverse tamoxifeninduced uterine changes in postmenopausal breast cancer patients, Ann. Oncol. 16 (2005) 70-74

[19] L. Morales, R. Paridaens, D. Timmerman, P. Neven, Aromatase inhibitors and postmenopausal breast cancer patients with tamoxifen-induced endometrial pathology, Clin. Cancer Res. 12 (2006) 5603.

[20] M. Prasad, H. Wang, W. Douglas, R.R. Barakat, L.H. Ellenson, Molecular genetic characterization of tamoxifen-associated endometrial cancer, Gynecol. Oncol. 96 (2005) 25-31.

[21] S.A. Salama, M. Kamel, M. Awad, A.H. Nasser, A. Al-Hendy, S. Botting, C. Arrastia, Catecholestrogens induce oxidative stress and malignant transformation in human endometrial glandular cells: protective effect of catechol-Omethyltransferase, Int. J. Cancer 123 (2008) 1246-1254

[22] B.C. Lin, M. Suzawa, R.D. Blind, S.C. Tobias, S.E. Bulun, T.S. Scanlan, H.A. Ingraham, Stimulating the GPR30 estrogen receptor with a novel tamoxifen analogue activates SF-1 and promotes endometrial cell proliferation, Cancer Res. 69 (2009) 5415-5423.

[23] V. Speirs, E.F. Adams, M.C. White, The anti-estrogen tamoxifen blocks the stimulatory effects of interleukin- 6 on 17 beta-hydroxysteroid dehydrogenase activity in MCF-7 cells, J. Steroid Biochem. Mol. Biol. 46 (1993) 605-611.

[24] S.J. Santner, R.J. Santen, Inhibition of estrone sulfatase and 17 betahydroxysteroid dehydrogenase by antiestrogens, J. Steroid Biochem. Mol. Biol. 45 (1993) 383-390.

[25] M.M. Montano, N.R. Bianco, H. Deng, B.M. Wittmann, L.C. Chaplin, B.S. Katzenellenbogen, Estrogen receptor regulation of quinone reductase in breast cancer: implications for estrogen-induced breast tumor growth and therapeutic uses of tamoxifen, Front. Biosci. 10 (2005) 1440-1461.

[26] P.G. Allen, J.M. Kolesar, NAD(P)H: quinone oxidoreductase enhances proliferation inhibition by 4-hydroxytamoxifen, Anticancer Res. 22 (2002) 1475-1480

[27] I. Campisi, O.M. Granata, L. Cocciadiferro, M. Calabro, L.M. Polito, G. Carruba, 16alpha-hydroxyestrone inhibits estrogen sulfotransferase activity in human liver cancer cells, Ann. N.Y. Acad. Sci. 1155 (2009) 237-241.

[28] S. Kyo, M. Nakamura, T. Kiyono, Y. Maida, T. Kanaya, M. Tanaka, N. Yatabe, M. Inoue, Successful immortalization of endometrial glandular cells with normal structural and functional characteristics, Am. J. Pathol. 163 (2003) 2259-2269.
[29] X. Xu, L.K. Keefer, R.G. Ziegler, T.D. Veenstra, A liquid chromatography-mass spectrometry method for the quantitative analysis of urinary endogenous estrogen metabolites, Nat. Protocol 2 (2007) 1350-1355.

[30] M. Zahid, N.W. Gaikwad, M.F. Ali, F. Lu, M. Saeed, L. Yang, E.G. Rogan, E.L. Cavalieri, Prevention of estrogen-DNA adduct formation in MCF-10F cells by resveratrol, Free Radic. Biol. Med. 45 (2008) 136-145.

[31] A.H. Eliassen, R.G. Ziegler, B. Rosner, T.D. Veenstra, J.M. Roman, X. Xu, S.E Hankinson, Reproducibility of fifteen urinary estrogens and estrogen metabolites over a 2- to 3-year period in premenopausal women, Cancer Epidemiol. Biomarkers Prev. 18 (2009) 2860-2868.

[32] Y. Shang, M. Brown, Molecular determinants for the tissue specificity of SERMs, Science 295 (2002) 2465-2468.

[33] Y. Shang, Molecular mechanisms of oestrogen and SERMs in endometrial carcinogenesis, Nat. Rev. Cancer 6 (2006) 360-368.

[34] H.L. Bradlow, R.J. Hershcopf, C.P. Martucci, J. Fishman, Estradiol 16 alphahydroxylation in the mouse correlates with mammary tumor incidence and presence of murine mammary tumor virus: a possible model for the hormonal etiology of breast cancer in humans, Proc. Natl. Acad. Sci. U.S.A. 82 (1985) 6295-6299.

[35] A.O. Mueck, H. Seeger, Breast cancer: are estrogen metabolites carcinogenic? Climacteric 10 (Suppl. 2) (2007) 62-65

[36] M.J. Scandlyn, E.C. Stuart, T.J. Somers-Edgar, A.R. Menzies, R.J. Rosengren, A new role for tamoxifen in oestrogen receptor-negative breast cancer when it is combined with epigallocatechin gallate, Br. J. Cancer 99 (2008) 1056-1063.

37] S.S. Lee, H.G. Jeong, K.H. Yang, Effects of estradiol and progesterone on cytochrome P4501A1 expression in Hepa 1c1c7 cells, Biochem. Mol. Biol. Int 45 (1998) 775-781.

[38] M.S. Ricci, D.G. Toscano, C.J. Mattingly, W.A. Toscano Jr., Estrogen receptor reduces CYP1A1 induction in cultured human endometrial cells, J. Biol. Chem. 274 (1999) 3430-3438.

[39] B.J. Fuhrman, X. Xu, R.T. Falk, S.E. Hankinson, T.D. Veenstra, L.K. Keefer, R.G. Ziegler, Stability of 15 estrogens and estrogen metabolites in urine samples under processing and storage conditions typically used in epidemiologic studies, Int. J. Biol. Markers 25 (2010) 185-194

[40] M. Maggiolini, A. Vivacqua, G. Fasanella, A.G. Recchia, D. Sisci, V. Pezzi, D. Montanaro, A.M. Musti, D. Picard, S. Ando, The G protein-coupled receptor GPR30 mediates c-fos up-regulation by $17 \mathrm{beta}$-estradiol and phytoestrogens in breast cancer cells, J. Biol. Chem. 279 (2004) 27008-27016.

[41] E.J. Filardo, J.A. Quinn, A.R. Frackelton Jr. K.I. Bland, Estrogen action via the $G$ protein-coupled receptor, GPR30: stimulation of adenylyl cyclase and cAMP-mediated attenuation of the epidermal growth factor receptor-to-MAPK signaling axis, Mol. Endocrinol. 16 (2002) 70-84.

[42] C.M. Revankar, D.F. Cimino, L.A. Sklar, J.B. Arterburn, E.R. Prossnitz, A transmembrane intracellular estrogen receptor mediates rapid cell signaling, Science 307 (2005) 1625-1630.

[43] A. Sourla, S. Luo, C. Labrie, A. Belanger, F. Labrie, Morphological changes induced by 6 -month treatment of intact and ovariectomized mice with tamoxifen and the pure antiestrogen EM-800, Endocrinology 138 (1997) 5605-5617.

[44] S. Luo, C. Martel, A. Sourla, S. Gauthier, Y. Merand, A. Belanger, C. Labrie, F. Labrie, Comparative effects of 28-day treatment with the new anti-estrogen EM-800 and tamoxifen on estrogen-sensitive parameters in intact mice, Int. J. Cancer 73 (1997) 381-391.

[45] B.T. Zhu, A.H. Conney, Functional role of estrogen metabolism in target cells: review and perspectives, Carcinogenesis 19 (1998) 1-27.

[46] J.A. Doherty, N.S. Weiss, R.J. Freeman, D.A. Dightman, P.J. Thornton, J.R. Houck L.F. Voigt, M.A. Rossing, S.M. Schwartz, C. Chen, Genetic factors in catecho estrogen metabolism in relation to the risk of endometrial cancer, Cancer Epidemiol. Biomarkers Prev. 14 (2005) 357-366

[47] E. Taioli, A. Im, X. Xu, T.D. Veenstra, G. Ahrendt, S. Garte, Comparison of estrogens and estrogen metabolites in human breast tissue and urine, Reprod. Biol. Endocrinol. 8 (2010) 93.

[48] Y. Tsuchiya, N. Nakajima, S. Kyo, T. Kanaya, M. Inoue, T. Yokoi, Human CYP1B1 is regulated by estradiol via estrogen receptor, Cancer Res. 64 (2004) 3119-3125.

[49] S. Harmsen, I. Meijerman, J.H. Beijnen, J.H. Schellens, Nuclear receptor mediated induction of cytochrome P450 3A4 by anticancer drugs: a key role for the pregnane X receptor, Cancer Chemother. Pharmacol. 64 (2009) 35-43.

[50] R.S. Sane, D.J. Buckley, A.R. Buckley, S.C. Nallani, P.B. Desai, Role of human pregnane $\mathrm{X}$ receptor in tamoxifen- and 4-hydroxytamoxifen-mediated CYP3A4 induction in primary human hepatocytes and LS174T cells, Drug Metab. Dispos. 36 (2008) 946-954.

[51] S.P. Sripathy, L.J. Chaplin, N.W. Gaikwad, E.G. Rogan, M.M. Montano, hPMC2 is required for recruiting an ERbeta coactivator complex to mediate transcriptional upregulation of NQO1 and protection against oxidative DNA damage by tamoxifen, Oncogene 27 (2008) 6376-6384.

[52] T.M. Kian, I. Rogatsky, C. Tzagarakis-Foster, A. Cvoro, J. An, R.J. Christy, K.R. Yamamoto, D.C. Leitman, Estradiol and selective estrogen receptor modulators differentially regulate target genes with estrogen receptors alpha and beta, Mol. Biol. Cell 15 (2004) 1262-1272.

[53] B.S. Katzenellenbogen, J.A. Katzenellenbogen, Biomedicine. Defining the " $\mathrm{S}$ " in SERMs, Science 295 (2002) 2380-2381.

[54] M.M. Montano, H. Deng, M. Liu, X. Sun, R. Singal, Transcriptional regulation by the estrogen receptor of antioxidative stress enzymes and its functional implications, Oncogene 23 (2004) 2442-2453.

[55] W.J. Welboren, H.G. Stunnenberg, F.C. Sweep, P.N. Span, Identifying estrogen receptor target genes, Mol. Oncol. 1 (2007) 138-143. 